\title{
Desenvolvimento e caracterização de queijo tipo petit suisse de soja comum e de soja livre de lipoxigenase, enriquecidos com cálcio
}

\author{
Characterization and elaboration of ordinary soy and lipoxigenase-free \\ soybean petit suisse cheese enriched with calcium
}

\author{
Débora Alexandrino BOATTO ${ }^{1 \star}$, Michele Cristiane $\mathrm{MESOMO}^{3}$, \\ Grasiele Scaramal MADRONA ${ }^{1}$, Ivanise Guilherme BRANCO ${ }^{2}$, Paula Toshimi MATUMOTO-PINTRO ${ }^{4}$
}

\section{Resumo}

Neste trabalho foi desenvolvido queijo tipo petit suisse de soja, utilizando soja comum e soja livre de lipoxigenase, enriquecido com cálcio e polpa de morango. As formulações foram caracterizadas quanto à composição química e centesimal (pH, acidez, umidade, cinzas, proteína, teor de cálcio, composição e identificação dos ácidos graxos) e avaliação sensorial. Os resultados obtidos mostraram diferença na composição centesimal, disponibilidade de cálcio e atributos sensoriais para os petit suisse produzidos a partir dos diferentes cultivares. As melhores características nutricionais e a maior aceitação foram verificadas para a formulação elaborada com soja livre de lipoxigenase.

Palavras-chave: queijo petit suisse; soja; composição química; composição centesimal.

\begin{abstract}
A soy petit suisse cheese was elaborated using ordinary soybean and lipoxygenase-free soybean and enriched with calcium and strawberry pulp. The formulations were characterized in terms of chemical composition and centesimal composition ( $\mathrm{pH}$, acidity, moisture, ash, protein, calcium content, composition, and identification of fatty acids), and sensory evaluation. The results showed differences in the centesimal composition, calcium availability, and sensory attributes for the petit suisse cheese produced from the different cultivars. The best nutritional characteristics and greater acceptance were reported for the formulation prepared with soy-free lipoxygenase.

Keywords: petit suisse cheese; soybean; chemical composition; centesimal composition.
\end{abstract}

\section{Introdução}

A exigência por alimentos com composição nutricional balanceada, e que possam oferecer benefícios adicionais à saúde, é manifestada intensamente pelos consumidores atuais. Portanto, o desenvolvimento de produtos com características especiais, como o petit suisse a partir do extrato hidrossolúvel de soja, torna-se importante por aspectos econômicos e nutricionais.

O consumo nacional de queijo petit suisse tradicional, em 2005, foi de R\$ 404 milhões (MILKNET, 2008), sendo este um produto consumido como sobremesa e dirigido principalmente ao publico infantil. Já a produção mundial de soja, segundo a United States Department of Agriculture (USDA, 2008), é de 233,50 milhões de toneladas, sendo o Brasil o segundo maior produtor mundial com 58,80 milhões de toneladas, na safra de 2006/2007 (CENTRO..., 2008). A soja é uma matéria-prima com grande versatilidade que origina produtos e subprodutos muito usados pela agroindústria, indústria química e de alimentos.

A soja e os seus produtos vêm sendo amplamente estudados devido a seus valores nutricionais, sua utilização diversa nas indústrias e como alimento funcional (CIABOTTI et al., 2006). Além das propriedades nutricionais básicas, o consumo da soja produz efeitos benéficos à saúde, reduzindo os riscos de algumas doenças crônicas e degenerativas. A soja é rica em proteínas de boa qualidade e de baixo custo, possui ácidos graxos poliinsaturados, compostos fitoquímicos e é uma excelente fonte de minerais e vitaminas do complexo B. A sua composição e suas substâncias fitoquímicas (flavonoides) são de interesse das pesquisas devido à relação de consumo de soja e a redução dos riscos de doenças crônicas não infecciosas como as doenças cardiovasculares, alguns tipos de cânceres e osteoporoses (EMBRAPA SOJA, 2007; SILVA et al., 2006).

Produtos à base de soja também são uma alternativa aos intolerantes ao açúcar do leite de vaca, a lactose (4-O- $\beta$-Dgalactopiranosil-D-glucopiranose), devido à deficiência de uma enzima denominada $\beta$-galactosidase ou lactase. A lactose é um açúcar de doçura e solubilidade relativamente baixas e não pode ser absorvido diretamente a partir do intestino humano (MORIWAKI; MATIOLI, 2000).

Recebido para publicação em 1/8/2008

Aceito para publicação em 23/6/2009 (003758)

${ }^{1}$ Departamento de Engenharia Química, Universidade Estadual de Maringá - UEM, Maringá - PR, Brasil, E-mail: debora_boatto@yahoo.com.br

2 Engenharia de Alimentos, Universidade Estadual de Maringá - UEM, CEP 87020-900, Maringá - PR, Brasil

${ }_{3}$ Departamento de Engenharia de Alimentos, Universidade Estadual do Centro Oeste - UNICENTRO, CEP 85010-990, Guarapuava - PR, Brasil

${ }^{4}$ Departamento de Agronomia, Universidade Estadual de Maringá - UEM, Maringá - PR, Brasil

${ }^{*}$ A quem a correspondência deve ser enviada 
A substituição do leite de vaca pelo extrato hidrossolúvel de soja e seus derivados seria perfeita nutricionalmente quanto à quantidade e qualidade de proteínas. Porém, ao considerarmos a quantidade de micronutrientes como o cálcio, o extrato hidrossolúvel de soja não se torna adequado como substituto para o leite bovino, cujo conteúdo de cálcio é de $123 \mathrm{mg} .100 \mathrm{~mL}^{-1}$ (CASÉ et al., 2005). Cada $100 \mathrm{~mL}$ de extrato hidrossolúvel de soja contém 52 calorias, $2,5 \%$ de carboidratos, $3,4 \%$ de proteínas, 2,3\% de lipídios, $40 \mathrm{mg}$ de cálcio, $105 \mathrm{mg}$ de potássio e 1,2 mg de ferro, $40 \mathrm{mg}$ de vitamina $\mathrm{B} 1$ e $120 \mathrm{mg}$ de vitamina B2 (EMBRAPA SOJA, 2007). O consumo de quantidades necessárias de cálcio é de extrema importância devido à calcificação óssea, principalmente durante as primeiras décadas de vida e na prevenção de osteoporose em adultos (BAZZANI et al., 2007). Assim, devido a essa deficiência no teor de cálcio em produtos à base de soja, se faz necessário o enriquecimento com este componente. Porém é uma operação difícil, pois os sais desse mineral podem promover coagulação das proteínas das leguminosas (CASÉ et al., 2005).

Apesar da alta produtividade e de suas propriedades nutricionais e funcionais, a soja é pouco usada na dieta do brasileiro, pois apresenta sabor e odor característicos, conhecidos como beany flavor que desagrada o paladar ocidental. Esse sabor característico da soja é devido à presença de diversos compostos orgânicos nos grãos e também, em grande parte, proporcionado pelo resultado das atividades das isoenzimas lipoxigenases (LOX 1,2 e 3). A ação das isoenzimas sobre os ácidos graxos poli-insaturados presente na soja é um dos principais fatores responsáveis pelo aparecimento de compostos carboxílicos, os quais causam o sabor desagradável em grãos (EMBRAPA SOJA, 2007; MARTINS, 2002; CIABOTTI et al., 2006; SILVA et al. 2006).

Os estudos em melhoramento de plantas têm levado em consideração as características de um cultivar com sabores suaves, tamanhos de semente, teor de proteínas e redução ou ausência da enzima lipoxigenase (CARRÃO-PANIZZI, 2000; EMBRAPA SOJA, 2007). Os cultivares de soja recomendados para a alimentação humana não apresentam atividade da lipoxigenase.

Portanto, este trabalho teve por objetivo desenvolver um queijo tipo petit suisse obtido a partir do extrato hidrossolúvel de soja, usando soja comum e soja livre de lipoxigenase, visando verificar a influência da variedade do grão sobre a característica sensorial de sabor, composição química e centesimal do produto obtido. O enriquecimento com cálcio é interessante, pois o produto pode ser destinado às crianças em fase de crescimento, como também para indivíduos intolerantes a lactose, considerando que estes últimos são privados da principal fonte de cálcio na alimentação, o leite bovino.

\section{Material e métodos}

A preparação das amostras e as análises físico-químicas do queijo tipo petit suisse de soja, foram realizadas no Laboratório de Tecnologia de Transformação e Conservação de Produtos Agropecuários (TTCPA) do Departamento de Agronomia da Universidade Estadual de Maringá.
No Laboratório de Cromatografia de Alimentos do Departamento de Química da Universidade Estadual de Maringá, foram realizadas a composição centesimal, teor de cálcio, extração e transesterificação dos lipídios totais e análises cromatográficas do queijo tipo petit suisse de soja.

\subsection{Material}

\section{Matéria-prima}

Foram utilizados grãos de soja dos cultivares EMBRAPA 48 e BRS 213 produzidos na região noroeste do Paraná.

O cultivar de soja BRS 213 foi utilizado por não apresentar a enzima lipoxigenase. Já o EMBRAPA 48 foi escolhido por apresentar elevado potencial de produtividade e ser muito utilizado pela indústria para a alimentação humana, devido à alta oferta no mercado (FUNDAÇÃO MERIDIONAL, 2008).

\subsection{Métodos}

\section{Produção de extrato hidrossolúvel de soja}

A matéria-prima (soja em grão) foi limpa e aquecida à temperatura de $100{ }^{\circ} \mathrm{C}$ durante 5 minutos, antes do processamento para favorecer um produto derivado com melhor sabor (CARRÃO-PANIZZI et al., 1999, 2000; EMBRAPA, 2004). Após o pré-aquecimento, a soja foi triturada na proporção de 1:10 (WANG et al., 1997). O extrato foi filtrado, obtendo-se assim o extrato hidrossolúvel de soja que foi pasteurizado a $80^{\circ} \mathrm{C} / 10$ minutos.

\section{Produção do queijo tipo petit suisse de soja enriquecido com cálcio}

O extrato hidrossolúvel de soja foi coagulado com ácido lático $85 \%\left(1,5 \mathrm{~mL} .1000 \mathrm{~mL}^{-1}\right)$ a $80{ }^{\circ} \mathrm{C}$ por 10 minutos. Em seguida, foi realizada a filtração para a separação do coagulado e do soro.

Foram adicionados ao coagulado 30\% de açúcar, 20\% de polpa integral de morango (Polpa Norte), 600 ppm de cálcio quelato $21 \%$ Vitafarma, segundo Bazzani et al. (2007), corante natural Carmim de Cochonilha e essência artificial de morango (Fleischmann), sob agitação vigorosa por 1 minuto, obtendo-se a textura desejada do queijo tipo petit suisse.

\subsection{Análises físico-químicas}

\section{Acidez e pH}

As análises de acidez foram realizadas por titulação direta com solução de hidróxido de sódio $0,1 \mathrm{M}$, com o auxílio de solução de fenolftaleína como indicador e o valor de $\mathrm{pH}$ por leitura direta em pHmetro digital.

\section{Extração de lipídios totais}

Os lipídios totais foram extraídos conforme metodologia de Folch, Lees e Sloane Stanley (FLS) (1957). 


\section{Transesterificação dos lipídios totais}

$\mathrm{Na}$ transesterificação dos lipídios totais, os triacilgliceróis foram submetidos ao processo de transmetilação, conforme o método 5509 da ISO (INTERNATIONAL..., 1978) .

\section{Análise cromatográfica}

Os ésteres de ácidos graxos foram separados em um cromatógrafo gasoso 14-A (Shimadzu, Japão), equipado com coluna capilar de sílica fundida CP Sil-88 (50 m de comprimento, $0,25 \mathrm{~mm}$ de diâmetro interno e $0,25 \mu \mathrm{m}$ de biscianopropil polisiloxano) e detector de ionização de chama. Os fluxos dos gases foram de $1,2 \mathrm{~mL} /$ minuto para o gás de arraste $\mathrm{H}_{2}$, $30 \mathrm{~mL} /$ minuto para o gás auxiliar $\mathrm{N}_{2}$ e 30 e $300 \mathrm{~mL} /$ minuto para os gases da chama $\mathrm{H}_{2}$ e ar sintético, respectivamente. A razão de divisão da amostra foi de 1:100. As temperaturas do injetor e detector foram 220 e $230^{\circ} \mathrm{C}$, respectivamente. As injeções serão realizadas em duplicata e o volume de injeção será de $2 \mu \mathrm{L}$. As áreas dos picos serão determinadas utilizando-se um IntegradorProcessador CG-300 (Instrumentos Científicos CG).

\section{Identificação dos ácidos graxos}

A identificação dos ácidos graxos foi baseada na comparação dos tempos de retenção com os de ésteres metílicos de misturas padrão obtidas da Sigma - EUA e pelos valores de ECL "Equivalent Chain Lenght", conforme descrito por Visentainer e Franco (2006).

\section{Umidade, cinzas e proteínas}

As análises de umidade, cinza e proteína bruta foram realizadas conforme as técnicas da AOAC (ASSOCIATION..., 1999).

\subsection{Análise sensorial}

O teste afetivo de aceitação por escala hedônica foi aplicado em 26 provadores, expressando o grau de gostar e desgostar do produto. Foi utilizada uma escala de 9 pontos, variando desde 'desgostei extremamente' a 'gostei extremamente', contendo um ponto intermediário 'nem gostei e nem desgostei', segundo metodologia descrita pelo Instituto Adolfo Lutz (2005).

\subsection{Análise estatística}

As análises laboratoriais foram realizadas em triplicata e os resultados obtidos foram submetidos à análise de variância, sendo estudados por meio da comparação de médias com significância de $5 \%$ pelo Teste de Tukey, utilizando o programa estatístico SAEGDemo.

\section{Resultados e discussão}

\subsection{Composição centesimal e análises físico-químicas}

Os dados referentes a composição centesimal, análises físicoquímicas e teor de cálcio dos queijos tipo petit suisse de soja comum (Embrapa 48) e de soja livre de lipoxigenase (BRS 213), enriquecidos com cálcio se encontram na Tabela 1 .
De acordo com a Tabela 1, verificou-se que não ocorreu variação significativa entre os resultados obtidos para acidez total e conteúdo mineral (cinzas) entre o cultivar comum e o livre de lipoxigenase. No entanto, verificaram-se diferenças significativas $(\mathrm{p}<0,05)$ entre os cultivares na análise física de pH e na composição centesimal de umidade, proteína, gordura total, carboidrato e também no teor de cálcio.

A caracterização dos cultivares de soja quanto ao teor de gordura e proteína possibilita disponibilizar informações sobre os cultivares mais indicados para usos específicos, agrega valor qualitativo a esses produtos e viabiliza o aumento de sua participação no mercado. O maior teor de proteína e gordura para o queijo tipo petit suisse de soja, respectivamente 5,43 e $4,27 \%$, foram encontrados no cultivar Embrapa 48. Este cultivar é indicado para a alimentação humana devido a sua elevada produtividade e boas características do grão para obtenção de óleo e proteína. Porém, a enzima lipoxigenase presente no grão pode provocar sabor estranho nos seus derivados. Entretanto, o cultivar especial (ausência de lipoxigenase), também apresenta elevados teores de proteína e gordura total (Tabela 1), agregando a isto um melhor sabor pela não degradação dos ácidos graxos presentes pela ação da enzima.

O cultivar BRS 213, livre de lipoxigenase, apresentou diferença significativa $(\mathrm{p}<0,05)$ e maior teor de umidade que o cultivar Embrapa 48 (soja comum). Avaliando o processo de branqueamento seguido de maceração para obtenção do extrato hidrossolúvel, tem-se a indicação de que houve maior solubilização das proteínas e gordura total na soja comum, sendo o mesmo verificado por Ciabotti et al. (2006). Consequentemente, proporcionou maior agregação de água no queijo tipo petit suisse de soja o cultivar BRS 213, conferindo menores teores de proteína e gordura após a coagulação das proteínas, ou seja, no produto final.

O teor de cálcio apresentou diferença significativa $(\mathrm{p}<0,05)$ entre os cultivares estudados (Tabela 1) e, segundo Casé et al. (2005), o cálcio quelato apresenta ótima biodisponilidade (44\%), superando a do leite bonivo (27\%), além de ter alta solubilidade, não apresentando separação de fases e nem precipitação no extrato hidrossolúvel de soja. No entanto, o teor de cálcio no queijo tipo petit suisse de soja apresentou-se baixo, quando comparado ao fornecido pela literatura para extrato hidrossolúvel de soja, uma

Tabela 1. Análises físico-químicas, composição centesimal e teor de cálcio do queijo tipo petit suisse de soja enriquecido com cálcio.

\begin{tabular}{lcc}
\hline \multicolumn{1}{c}{ Análises } & \multicolumn{2}{c}{ Cultivares de soja } \\
\cline { 2 - 3 } & $\begin{array}{c}\text { Embrapa } 48 \\
(\text { Soja comum) }\end{array}$ & $\begin{array}{c}\text { BRS 213 } \\
\text { (Soja livre de lipoxigenase) }\end{array}$ \\
\hline $\mathrm{pH}$ & $4,30 \pm 0,02^{\mathrm{b}}$ & $4,42 \pm 0,05^{\mathrm{a}}$ \\
Acidez total (\%) & $6,26 \pm 0,25^{\mathrm{a}}$ & $6,02 \pm 0,36^{\mathrm{a}}$ \\
Umidade a $105^{\circ} \mathrm{C}(\%)$ & $67,53 \pm 0,04^{\mathrm{b}}$ & $69,43 \pm 0,05^{\mathrm{a}}$ \\
Cinzas (\%) & $0,35 \pm 0,02^{\mathrm{a}}$ & $0,33 \pm 0,02^{\mathrm{a}}$ \\
Proteína bruta (\%) & $5,43 \pm 0,03^{\mathrm{a}}$ & $4,70 \pm 0,01^{\mathrm{b}}$ \\
Gordura total (\%) & $4,27 \pm 0,02^{\mathrm{a}}$ & $2,92 \pm 0,02^{\mathrm{b}}$ \\
Carboidrato $(\%)$ & $22,42 \pm 0,04^{\mathrm{b}}$ & $22,62 \pm 0,05^{\mathrm{a}}$ \\
Teor de cálcio (mg.100 $\left.\mathrm{g}^{-1}\right)$ & $14,45 \pm 0,03^{\mathrm{b}}$ & $24,88 \pm 0,02^{\mathrm{a}}$ \\
\hline * Carboidrato por diferença; letras distintas na mesma linha diferem entre si pelo teste \\
de Tukey a um nível de significância de $5 \%$.
\end{tabular}


Tabela 2. Composição de ácidos graxos dos queijos tipo petit suisse de soja comum e livre de lipoxigenase.

\begin{tabular}{lrr}
\hline \multicolumn{1}{c}{ Composição dos ácidos graxos (\%) } & \multicolumn{2}{c}{ Cultivares de soja } \\
\cline { 2 - 3 } & Embrapa 48 (Soja comum) & BRS 213 (Soja livre de lipoxigenase) \\
\hline Ácidos graxos saturados & $15,16 \pm 0,07^{\mathrm{a}}$ & $15,53 \pm 0,17^{\mathrm{a}}$ \\
Ácidos graxos monoinsaturados & $26,64 \pm 0,07^{\mathrm{a}}$ & $18,18 \pm 1,09^{\mathrm{b}}$ \\
Ácidos graxos polinsaturados & $58,25 \pm 0,11^{\mathrm{b}}$ & $66,38 \pm 1,29^{\mathrm{a}}$ \\
Ácidos graxos ômega-3 & $5,52 \pm 0,09^{\mathrm{b}}$ & $7,68 \pm 0,12^{\mathrm{a}}$ \\
Ácidos graxos ômega-6 & $52,72 \pm 0,20^{\mathrm{b}}$ & $58,70 \pm 1,31^{\mathrm{a}}$ \\
Razão entre ácidos graxos poliinsaturados e monoinsaturados & $3,84 \pm 0,00^{\mathrm{b}}$ & $4,28 \pm 0,02^{\mathrm{a}}$ \\
Razão entre ácidos graxos ômega-6 e & $9,55 \pm 0,02^{\mathrm{a}}$ & $7,64 \pm 0,03^{\mathrm{b}}$ \\
\hline
\end{tabular}

Letras distintas na mesma linha diferem entre si pelo teste de Tukey a um nível de significância de 5\%.

vez que este derivado de soja apresenta $40 \mathrm{mg} .100 \mathrm{~mL}^{-1}$, segundo EMBRAPA SOJA (2007). A Tabela 1 mostra que o queijo tipo petit suisse de soja comum, com maior teor de proteína e gordura, apresentou menor concentração de cálcio. Em contrapartida, o queijo tipo petit suisse de soja livre de lipoxigenase, com menor teor de proteína e gordura, apresentou maior teor de cálcio $24,88 \mathrm{mg} \cdot 100 \mathrm{~g}^{-1}$. Foi possível então, verificar a interação entre a proteína, gordura e o mineral cálcio no momento da formulação, tornando o menos disponível no derivado de soja comum.

\subsection{Composição dos ácidos graxos}

Atualmente, a busca de fontes alternativas e complementares de ácidos graxos poli-insaturados ômega-3 (AGPIs n-3) tornou-se uma necessidade a fim de estar alterando a razão entre os ácidos ômega-6/ômega-3 (AGPI n-6/n-3) ingeridos. Durante muitas gerações, e desde os povos da antiguidade, essa razão manteve-se em 1:1. Com o aperfeiçoamento das tecnologias de extração e desodorização de óleos vegetais, houve um desequilíbrio da razão n-6/n-3, passando a 17:1, observada ultimamente nas dietas ocidentais, promovendo drásticas consequências à saúde pública, como incrementos no colesterol sanguíneo, acompanhado de hipertensão arterial, que são as duas principais condições predisponentes às doenças coronarianas (SIMOPOULOS, 2002).

Quanto à composição de ácidos graxos, foi possível analisar pela Tabela 2 que o cultivar de soja livre de lipoxigenase (BRS 213) diferiu estatisticamente $(\mathrm{p}<0,05)$ do cultivar de soja comum, em relação à composição de ácidos graxos, com exceção do teor de ácidos graxos saturados. Verificou-se que o cultivar BRS 213 apresentou o maior resultado para os ácidos graxos do grupo ômega-3, contribuindo assim para o equilíbrio metabólico e síntese de ácidos graxos poli-insaturados de cadeia longa, uma vez que as enzimas de dessaturação e elongação têm maior afinidade por este grupo de ácido graxo, caracterizando-a como o cultivar que apresenta melhor característica nutricional, como melhor fonte de ácidos graxos poli-insaturados, ômega-3, ômega-6, maior razão poli-insaturados/monoinsaturados e menor razão n-6/n-3, estando estes resultados de acordo com os encontrados por Martin et al.(2006).

Os cultivares com ausência de lipoxigenase ou de sabor mais suave produzem produtos com características sensoriais de maior aceitação pelo consumidor (MARTINS, 2002). Os cultivares de soja recomendados para a alimentação humana apresentam menos liberação de hexanal, um dos compostos voláteis que é produzido na degradação dos ácidos graxos pelas isoenzimas lipoxigenases (YUAN; CHANG, 2006).

\subsection{Análise sensorial}

A análise sensorial expressou, através da escala hedônica de nove pontos, nota de 7,08 , gostei regularmente, para o queijo tipo petit suisse de soja elaborado a partir do cultivar BRS $213 \mathrm{e}$ de 4,54, entre desgostei ligeiramente e nem gostei e desgostei, para o do cultivar Embrapa 48. Pelo teste de Tukey, com 5\% de significância, verificou-se a existência de diferença significativa entre os dois produtos formulados. Sendo assim, é possível confirmar a reprovação do sabor característico de soja pelo paladar ocidental, presente na soja comum pela presença da enzima lipoxigenase e oxidação dos lipídios.

\section{Conclusões}

A elaboração de queijo tipo petit suisse de soja, produzido a partir de cultivares diferentes, comum e livre de lipoxigenase, apresentou diferenças significativas em relação à composição centesimal, disponibilidade de cálcio e atributos sensoriais.

O cultivar BRS 213, livre de lipoxigenase, apresentou melhor característica nutricional devido à sua composição de ácidos graxos e na disponibilidade de cálcio.

O queijo tipo petit suisse de soja com maior aceitação foi elaborado a partir de soja especial, livre da enzima lipoxigenase (BRS 213), reduzindo o sabor característico de soja.

\section{Referências bibliográficas}

ASSOCIATION OF OFFICIAL ANALYTICAL CHEMISTS - AOAC. Official Methods of Analysis. 16 ${ }^{\text {th }}$ ed. Washington, 1999.

BAZZANI, C. S. R. et al. Desenvolvimento e caracterização de um 'iogurte de soja' enriquecido com cálcio, sabor amora. Higiene Alimentar, v. 21, n. 155, p. 84-91, 2007.

CARRÃO-PANIZZI, M. C. Melhoramento genético da soja para a obtenção de cultivares mais adequados ao consumo humano. Revista Brasileira de Nutrição Clínica, v. 15, p. 330-340, 2000.

CARRÃO-PANIZZI, M. C. et al. Effects of isoflavones on beany flavor and astringency of soymilk and cooked whole soybean grains. Pesquisa Agropecuária Brasileira, v. 34, n. 6, p. 1045-1052, 1999.

CASÉ, F. et al. Produção de 'leite' de soja enriquecido com cálcio. Ciência e Tecnologia de Alimentos, v. 25, n. 1, p. 86-91, 2005.

CENTRO DE INTELIGÊNCIA DE SOJA - CISOJA. Soja: produção mundial. 2008. Disponível em: <http://www.cisoja.com.br/ downloads/c_producao_mundial_safras_20062007_e_20052004. pdf>. Acesso em: 08 fev. 2008. 
CIABOTTI, S. et al. Avaliações químicas e bioquímicas dos grãos extratos e tofus de soja comum e de soja livre de lipoxigenase. Ciência Agrotecnológica, v. 30, n. 5, p. 920-929, 2006.

EMBRAPA SOJA. Soja na Alimentação. Londrina, 2007. Disponível em: <http://www.cnpso.embrapa.br/soja_alimentacao/index.php $>$. Acesso em: 07 abr. 2007.

EMBRAPA SOJA. Soja na alimentação. Londrina, 2004. Disponível em: <http:www.cnpso.embrapa.Br/soja_alimentação/index.php>. Acesso em: 19 abr. 2004.

FOLCH, J.; LEES, M.; SLOANE STANLEY, G. H. A simple method for the isolation and purification of total lipides from animal tissues. Journal Biological Chemistry, v. 226, n. 1, p. 497-509, 1957.

FUNDAÇÃO MERIDIONAL. Cultivares de soja 2007/2008 região centro-sul. Londrina: Embrapa Soja, 2008.

INSTITUTO ADOLFO LUTZ - IAL. Normas Analíticas do Instituto Adolfo Lutz. 4. ed. São Paulo, 2005. (Métodos Químicos e Físicos para Análise de Alimentos. v. 1).

INTERNATIONAL ORGANIZATION FOR STANDARDIZATION ISO 5509: Animal and vegetable fats and oils preparation of methyl esters of fatty acids Geneve, 1978, p. 1-6.

MARTIN, C. A. et al. Ácidos graxos polinsaturados ômega-3 e ômega-6: importância e ocorrência em alimentos. Revista de Nutrição, v. 19, n. 6, p. 761-770, 2006.

MARTINS, C. A. O Efeito da eliminação genética das lipoxigenases das sementes sobre as características agronômicas da soja. Pesquisa Agropecuária Brasileira, v. 37, n. 10, p. 1389-1398, 2002.
MILKNET. Petit Suisse: Danone continua lider. 2008. Disponível em: $<$ http://www.milknet.com.br/?pg=noticia\&id=2851 $>$. Acesso em: 13 maio 2008.

MORIWAKI, C.; MATIOLI, G. Influência da $\beta$-galactosidase na tecnologia do leite e na má digestão da lactose. Arquivo Ciências da Saúde, v. 4, n. 3, p. 283-290, 2000.

SILVA, M. S. et al. Composição química e valor protéico do resíduo de soja em relação ao grão de soja. Ciência e Tecnologia de Alimentos, v. 26, n. 3, p. 571-576, 2006.

SIMOPOULOS, A. P. The importance of the ratio of omega-6/omega-3 essescial fatty acids. Biomedicine Pharmacother, v. 56, p. 365-379, 2002.

UNITED STATES DEPARTMENT OF AGRICULTURE - USDA. Disponível em: <http://www.usda.gov>. Acesso em: abr. 2008.

VISENTAINER, J. V.; FRANCO, M. R. B. Ácidos Graxos em Óleos e Gorduras: Identificação e Quantificação. São Paulo: Varela, 2006. v. $1.124 \mathrm{p}$.

WANG, S. et al. Efeito da proporção soja: água e aquecimento sobre o rendimento e qualidade protéica do leite de soja. Pesquisa Agropecuária Brasileira, v. 32, n. 10, p. 1059-1069, 1997.

YUAN, S.; CHANG, S. K. C. Select odor compounds in soymilk as affected by chemical composition and lipoxygenases in five soybean materials. Journal of Agricultural and Food Chemistry, v. 55, p. 426-431, 2007. 